\title{
Article \\ Unbalanced Current Sharing Control in Islanded Low Voltage Microgrids
}

\author{
Foad Najafi ${ }^{1}\left[{ }^{*}\right.$ and Matthias Fripp ${ }^{1}(\mathbb{D}$ \\ 1 Department of Electrical Engineering, University of Hawaii at Manoa, Honolulu, Hawaii, 96822 \\ * Correspondence: fnajafi@hawaii.edu
}

Version September 5, 2018 submitted to Preprints

\begin{abstract}
This paper reports a new control strategy to improve sharing of unbalanced currents in islanded LV microgrids. This technique provides fast and effective sharing of positive-, negative- and zero-sequence currents, and is the first example of zero-sequence current sharing in the literature. The controllers are designed in the stationary frame. The control structure consists of four loops; 1) the current controller; 2) the voltage controller; 3) the droop controller and the 4) negative and zero sequence current controllers. The output current is considered unknown for the controller and is added to the control system as a disturbance. The proposed controller features a high gain in fundamental and harmonic frequencies, hence a good voltage quality is obtained in the presence of unbalanced and nonlinear loads. To this aim, a proportional-resonant (PR) controller is adopted as the current controller. By using a multi-resonant controller as current controller, a unified control structure is obtained which is suitable for both grid-connected and islanded modes. The voltage controller is designed using a resonant controller so that the voltage can have low VUF and THD in the presence of unbalanced and nonlinear loads. Furthermore, in this paper droop method is applied to the control structure to share real and reactive powers. Simulation studies show that the conventional droop method cannot share the oscillatory part of the output power that is due to the presence of unbalanced loads in the microgrid. This paper relies on using zero and negative sequence virtual impedance controller to share the oscillatory part of output power. By using zero-sequence virtual impedance controller (ZSVIC) and negative-sequence virtual impedance controller (NSVIC), the zero and negative sequence currents in the microgrid are controlled and shared effectively. By compensating zero- and negative-sequence currents locally, the flow of these currents in the microgrid is minimized, and the overall power quality of the islanded LV microgrid is improved.
\end{abstract}

Keywords: Distributed generation, LV microgrid, negative-sequence current, zero-sequence current, power sharing, unbalance load, voltage control.

\section{Introduction}

Distributed energy resources (DERs) are small power sources to provide the required power to meet the increasing demand. Different power quality issues are appeared after placing DERs [1,2]. Various research works have been performed to deal with these matters. Microgrids are small-scale power systems with local resources (DERs) for production, consumption, and storage, that can work connected to the main grid or islanded [3]. An improved indicator was proposed in [4] to estimate the voltage stability margin of a two-bus system based on both saddle-node and limited induced bifurcations. A new concept named reduced islanded microgrid network was used for generalization of the proposed index ton-bus islanded microgrids and a development power flow algorithm by splitting these networks. Consideration of the system maximum loadability, a droop-controlled based method was proposed in [5] in islanded microgrids for optimal power flow problems. An optimal control algorithm was presented in [6] for DERs to improve the power quality and reduce the energy costs of a hybrid AC-DC microgrid. Authors in [7] proposed a control method based on Lyapunov control theory to investigate the stability of the DG units while operating alongside the utility grid. 
In [8], The passivity-based control technique is utilized to analyze the dynamic and steady-state behavior during integration with the power grid. By applying this technique, the harmonic and reactive power component can be supplied with a fast dynamic response. Power quality issues are among the most challenging topics of controlling microgrids, especially in the islanded mode. Power quality problem consists of two main type: nonlinear and unbalances load. The proliferation of single-phase and nonlinear loads in the microgrids has made important challenges regarding the power quality of these networks [9]. In the grid-connected mode, if the microgrids cannot manage to compensate the current absorbed by nonlinear and unbalanced loads easily, the main grid can easily offset these currents. However, in the islanded mode, the microgrid itself is due to compensating the currents absorbed by nonlinear and unbalanced loads. In the islanded microgrids, power-sharing is more important compared to the grid-connected microgrids due to the limited capacity of the DG units hosted by the islanded microgrid in particular in the presence of unbalanced and harmonic loads [10].

When unbalance current increases proportional to the total current of the system, the voltage unbalances on some part of the system emerges[11]. Since the total capacity of islanded microgrid is limited, a small portion of single loads can make islanded microgrid severely unbalanced.

The problem that zero and negative sequence current create are [12]: 1: Increase the loss in the system, therefore increase the temperature in induction motors and transforms. 2: Vibrating induction motors which cause mechanical tension which reduces the lifetime of electric motors. 3: Reduction in power factor which is accompanied with more KVA demand. If there is a delta or grounded-star connection, the zero sequence current is eliminated. However, if there is no such connection, both zero and negative sequence current exist in the lines.

In these cases, the control performance of Voltage Source Inverter (VSI) would be influenced, leading to deteriorative power quality of microgrid. Therefore, it is necessary to develop the similar strategy to improve the power quality for microgrid in unbalanced conditions. Therefore, we need to have a controller that can share unbalanced current between all or part of sources in islanded microgrids[13].

A microgrid must be able to keep working under the unbalanced condition without any performance degradation, while the voltage unbalanced factor (VUF) should be held less than 2 percent for sensitive loads [14]. Therefore, the unbalanced current sharing strategy should consider this fact and do not let voltage unbalance increases from the threshold in any part of islanded microgrid.

The first step in a proper power sharing is to control the voltage and frequency [15] effectively. Several studies are conducted on unbalanced control strategy with second PI controllers to suppress the negative sequence components for an inverter with unbalance load[16,17], in which the voltages and currents are transferred by symmetry transformation firstly, and then the positive sequence and the negative sequence components are controlled by different PI controllers. However, the compensation strategy is applied to the individual operating inverter. Besides Proportional-integral (PI), The predictive deadbeat (DB), and proportional-resonant (PR) control technics are among the existing DG control methods. The PR controller is more efficient for the compensation of multiple harmonics due to the inclusion of nonlinear and unbalanced loads $[18,19]$. The next step toward uneven current sharing is managing fundamental power components, i.e., Active and Reactive power.

Active and reactive power sharing on Islanded microgrids control divides into two main strategies. The first method consists of strategies with communication in which each distributed generation unit sends data to a center, and the center decides for each unit to how much power each unit should produce. Another communication method is master-slave in which the master unit defines the voltage and frequency for the slave unit. The problem with the communication-based unit is that it needs transmission lines. Therefore, if the connection line is lost, the power management is interrupted [20]. Another problem with the communication-based method is that by adding a new source to the system, the whole system should be scheduled again. The other control method of microgrids are methods without communication. 
One of the most important types of the control method in this class is droop method which is inspired by the behavior synchronous method. One of the main advantages of droop controller is its plug-and-play specification. It means that adding new sources doesn't need new scheduling so this method is more reliable than communication-based methods. In this paper, we use droop method to share main power component such as active and reactive power. [21] proposes a new dynamic droop controller with the integration of SEMS/battery hybrid design to have a more stable frequency response in the Islanded microgrid while the battery lifetime increases. [22] proposes adaptive droop control with local measurement instrument to achieve genuine power sharing while reducing losses in the microgrid.

[20] propose a method to optimize droop coefficient to minimize the overall operation cost of islanded microgrid. In [23], the aim is to reduce frequency deviation in droop-based islanded microgrid with a mixed-integer linear programming method. In [24] a phase-angle droop control scheme is proposed to decrease system vulnerability in a severe situation such as storms or other natural disasters.

The conventional droop method is just based on proportional terms. To improve the speed response and accuracy of droop method, derivative and integral terms can be added to the droop $[25,26]$. Conventional droop is inspired by the ordinary network with rotating synchronous machine where the rotating inertia is coupled with the network, e.g., the inertia of synchronous machines. Therefore, the $\mathrm{P} / \mathrm{f}$ droop control is dependent on the kinetic energy of the synchronous machine inertia. In an electronically interfaced microgrid, generally, less inertia is available. In larger microgrids, e.g., medium voltage microgrids, there is enough inertia thorough inductive line and larger scale of microgrids to connect $\mathrm{P}$ to the phase angle through frequency. However, in small-scale microgrids which usually are Low Voltage microgrids, this linkage is not strong enough since there is not enough inductance in the network and Microgrids are mostly resistive [27]. Therefore, the active power/ Voltage and reactive power/ frequency are becoming more popular in Low Voltage networks [28].

In conventional droop, since the voltage is not the same in all the network, the accuracy of reactive power sharing degrades [29]. Conversely, in $\mathrm{P} / \mathrm{V}$ and $\mathrm{Q} / \mathrm{f}$ droop, the accuracy of active power sharing degrades. There is a trade-off between the accuracy of active power sharing and droop parameters (deviation from the normal frequency and voltage value parameters). I.e., if the droop slopes are higher, the accuracy of active power sharing for $\mathrm{P} / \mathrm{V}$ droop improves more. However, the voltage and frequency of the system will fluctuate more if a load is added or dropped. However, if the droop slopes are too low, the voltage and frequency deviation decrease but also it affects active power sharing negatively $[30,31]$. Although droop method is a practical way to share the main component of power such as active and reactive, it is unable to share another power component such as harmonic and unbalanced current in islanded microgrids.

To solve the unbalanced problem [32,33] suggested control method and strategies. [32], first investigate the relationship between active and reactive power oscillation in the presence of an unbalanced load and propose a plan to suppress the power oscillation that is caused by the unbalanced load. [33] offers a new strategy for unbalance and nonlinear load in islanded microgrid. One of the sources is responsible for supplying unbalanced and nonlinear current while other sources just share active and reactive power. The problem with this strategy is when unbalance load is far from the dedicated source, severe unbalance voltage will happen in the microgrid.

A plan for the scheduling of unbalanced microgrids is proposed in[34] build on the method of a multi-objective optimization problem, whose objective functions are related to specific services and requirements of the microgrid, such as cost minimization, power quality improvements, and energy savings. [23] employs adaptive Lyapunov function based control scheme to compensate the negative sequence current in some part of microgrid and by applying sliding mode based control scheme, regulate positive-sequence active and reactive power in the microgrid. One way of compensating unbalance current is using Active Power filters (APF) $[35,36]$. In this method, the negative sequence voltage, current is added to the series and shunt APF respectively. To compensate unbalance voltage, 
Table 1. Method Comparison.

\begin{tabular}{|c|c|c|c|c|c|}
\hline & Main Duties & Unbalanced Current Sharing Duties & $\begin{array}{c}\text { Unbalanced } \\
\text { Voltage Control }\end{array}$ & $\begin{array}{c}\text { Negative } \\
\text { Sequence } \\
\text { Sharing }\end{array}$ & $\begin{array}{c}\text { Negative and } \\
\text { Zero } \\
\text { Sequence } \\
\text { Sharing }\end{array}$ \\
\hline $\begin{array}{c}\text { UPS and single } \\
\text { Inverter }\end{array}$ & Voltage, frequency & $\begin{array}{c}\text { current sharing is not a problem } \\
\text { since there is only one unit to } \\
\text { provide the current }\end{array}$ & {$[33,35]$} & $\begin{array}{c}\text { Non } \\
\text { Apllicable }\end{array}$ & $\begin{array}{c}\text { Non } \\
\text { Apllicable }\end{array}$ \\
\hline Parallel Inverter & $\begin{array}{c}\text { Voltage, frequency, } \\
\text { circulating current } \\
\text { the main challenge is to stop } \\
\text { circulating unbalanced current } \\
\text { between units }\end{array}$ & {$[41,42,45,54]$} & {$[41,42,54]$} & [45] \\
\hline $\begin{array}{c}\text { Grid-Connected } \\
\text { MG }\end{array}$ & $\begin{array}{c}\text { Sharing active and } \\
\text { reactive power }\end{array}$ & $\begin{array}{c}\text { keeping unbalanced voltage under } \\
\text { control; if MG can not provide } \\
\text { enough unbalanced current, the } \\
\text { main grid can provide the rest }\end{array}$ & {$[23,32,34]$} & {$[23,32,34]$} & No Method \\
\hline Islanded MG & $\begin{array}{l}\text { voltage, frequency, } \\
\text { sharing active and } \\
\text { reactive power } \\
\text { control while unbalanced current is } \\
\text { shared only between DG units since } \\
\text { there is no main grid to provide } \\
\text { remaining unbalanced currents }\end{array}$ & {$[47,49,52,53,55]$} & {$[47,49,52,53$,} & $55]$ & $\begin{array}{c}\text { No Method } \\
\text { (focus of this } \\
\text { paper) }\end{array}$ \\
\hline
\end{tabular}

the[35] propose using two inverter structure. The first one connects as a shunt and the other connected as a series AFP. [37] uses model predictive control (MPC) technique to minimize the voltage unbalance. The MPC is combined with the V-I droop to provide a fast dynamic response. The concept of using virtual impedance becomes more and more prevalent in the control system of microgrids.

The first attempt to use virtual impedance concept return to [38] When virtual impedance was used to control a DC-DC converter. The use of virtual impedance is becoming more and more common in the case of controlling power electronic based instruments. One of the main application of virtual impedance is to help improve power sharing $[39,40]$. In microgrids the ratio of $x / r$ is low. Therefore, the accuracy of reactive power sharing decreases. By adding an inductive virtual impedance to the control loop, the accuracy of reactive load sharing improves significantly [39,41,42]. The virtual impedance is used to improve stability robustness against different scenarios in microgrid such as severe transient and fault situations[43,44]. Another use of virtual impedance is to promote load sharing among parallel converters[45-47]. in[48,49] adaptive virtual impedance is introduced to enhance power distribution further regardless of line impedance unbalances, linear and nonlinear loads.

It can be used to reduce harmonic/unbalanced current or voltage on the converters [50]. In [51,52], the negative-sequence voltage produced by negative-sequence impedance controller loop is injected directly to the reference signal of the voltage controller. The idea is to change negative-sequence impedance of each unit so that the amount of negative-sequence current of each DG is controlled. In [53], the above idea of using virtual negative-sequence impedance is used, but the negative-sequence voltage produced by the loop is directly injected to the control signal of the inverter.

To the best of our knowledge, the virtual impedance method has not been used for controlling the zero-sequence current in LV microgrids. In this paper, the virtual zero-sequence impedance together with the virtual negative-sequence impedance are used to control the zero- and negative-sequence currents in an LV microgrid. The proposed strategy relies on the fact that the adjacent DG of an unbalanced load should compensate the negative- and zero-sequence currents of that load. Moreover, if the negative- and zero-sequence currents of the load exceeds the maximum capacity of its own DGs, the remaining portion of the negative- and zero-sequence currents are shared among other DGs. Although there are numerous method in the literature about unbalance compensation, few of the focus on islanded microgrids. Table 1 shows summary of converter interfaced method that deals with unbalance problem. Most of the method is related to keeping the unbalanced voltage of the terminal of a single inverter or UPS below a limit by providing enough unbalanced current for the load. 
These control methods are not concerned about power-sharing and other power components since there is only one unit. Although these methods are effective to keep unbalanced voltage control, the effectiveness of them is not evaluated. Another group of research deals with the parallel inverters while feeding the loads connected to a common line. The control method in this group is more complex than the previous method.

The control strategy should not only be able to control voltage and frequency of each unit; they should be able to control circulating negative sequence current flowing in the system. Since the system is usually Three-wired, the zero sequence current is not a concern. The third group of methods deals with the grid-connected MG. the frequency and voltage are dictated by the main grid. Therefore, these control methods are in charge of active and reactive power and also other power components such as harmonic and unbalanced currents. Also, if the MG cannot provide enough unbalanced current, the main grid can compensate for it. The fourth group is the islanded-microgrids. The most complex control method belongs to this group. It control method not only should be able to control voltage and frequency by itself, but it should also be able to control and active and reactive power components and harmonic and unbalanced current altogether. One type of MG is low voltage ones. Since they are three-phase four-wired, zero sequences can flow in the network alongside negative and positive one when an unbalanced load is present in the network. From the very few papers that specifically focused on unbalanced current sharing, almost all of them focused on negative sequence current sharing and zero sequence current sharing is not addressed except only just one work.

\section{Methods}

\subsection{Multi-bus low voltage microgrid structure}

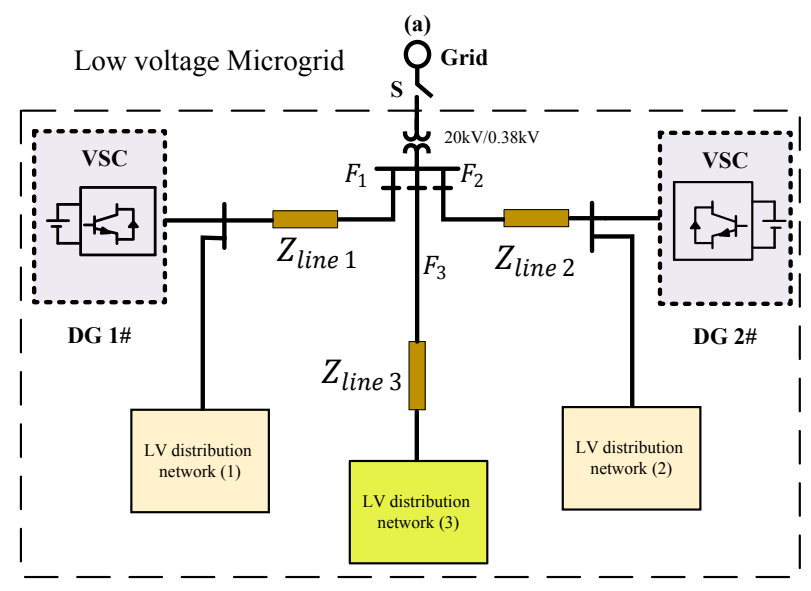

Figure 1. LV multi-bus MG consisting of two

DG units

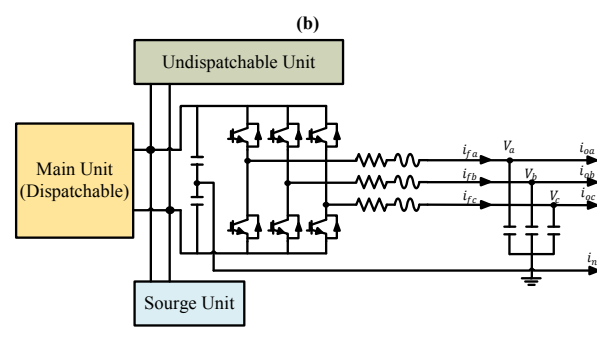

Figure 2. Three-phase four-wired inverter

Fig. 1 shows a single-line diagram of a multi-bus LV microgrid that consists of three LV feeders and two electronically-coupled three-phase four-wire DG units. Loads in the three radial feeders can be either balanced or unbalanced. The DG units connected via feeders $F 1$ and $F 2$ to the microgrid are assumed to be dispatchable. Therefore, they can provide any amount of real/reactive power within their pre-specified limits. Each unit has to maintain its voltage and frequency in the pre-specified level, while an accurate power-sharing is ensured through a decentralized method. The loads are connected to the microgrid through four wires. Therefore, the load current can have zero-sequence current in addition to the negative-sequence current when loads in the microgrid are unbalanced. In this paper, it is assumed that microgrid works in islanded mode of operation. Therefore, the microgrid is responsible for compensating zero- and negative-sequence currents of unbalanced loads. If the islanded microgrid does not compensate these currents, the voltage will be distorted. Table 3 shows the 
208

microgrid parameters. Each DG unit with its $L C$ filter is considered as a subsystem for the microgrid. In order to control each DG unit, the first step is to drive the dynamic model of each DG unit. Fig. 3 shows an equivalent circuit diagram of a three-phase four-wire DG subsystem. The objective is to design a feedback control that robustly regulates the load voltages while the load current is unknown. In [53], dynamic model for a three-phase three-wired network in the stationary reference frame $(\alpha \beta)$ is derived. Because this microgrid is a four-wire system, three separate state-space parameters are required to control the microgrid voltage.

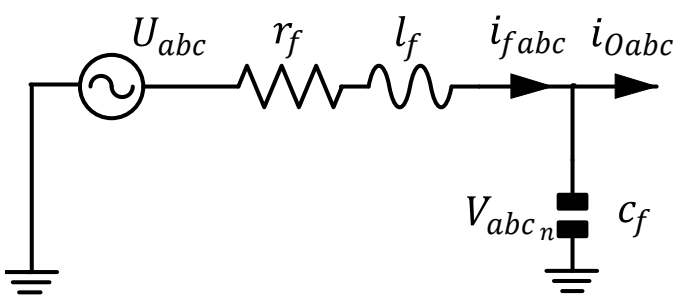

Figure 3. Single phase diagram of inverter.

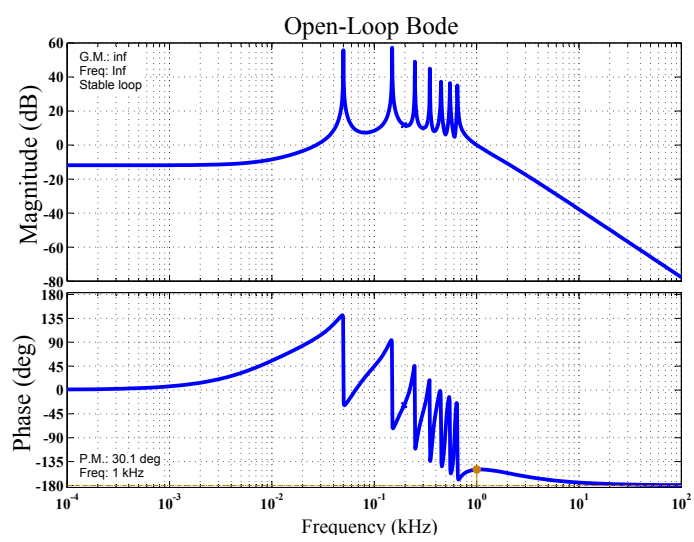

Figure 4. Bode diagram.

$$
\begin{aligned}
& \dot{\mathbf{X}}=\mathbf{A} \mathbf{X}+\mathbf{B U}+\mathbf{E W} \\
& \mathbf{Y}=\mathbf{C} \mathbf{X}
\end{aligned}
$$

where $\mathbf{X}=\left[v_{\alpha}, v_{\beta}, v_{0}, i_{f_{\alpha}}, i_{f_{\beta}}, i_{f_{0}}\right]^{T}, \mathbf{U}=\left[U_{\alpha}, U_{\beta}, U_{0}\right]^{T}, \mathbf{W}=\left[i_{o \alpha}, i_{o \beta}, i_{o_{0}}\right]^{T}, \mathbf{Y}=$ $\left[v_{\alpha}, v_{\beta}, v_{0}\right]^{T}$ and

$$
\begin{aligned}
\mathbf{A} & =\left[\begin{array}{cccccc}
0 & 0 & 0 & \frac{1}{C_{f}} & 0 & 0 \\
0 & 0 & 0 & 0 & \frac{1}{C_{f}} & 0 \\
0 & 0 & 0 & 0 & 0 & \frac{1}{C_{f}} \\
-\frac{1}{L_{f}} & 0 & 0 & -\frac{r_{f}}{L_{f}} & 0 & 0 \\
0 & -\frac{1}{L_{f}} & 0 & 0 & -\frac{r_{f}}{L_{f}} & 0 \\
0 & 0 & -\frac{1}{L_{f}} & 0 & 0 & -\frac{r_{f}}{L_{f}}
\end{array}\right] \\
\mathbf{B} & =\left[\begin{array}{ccc}
0 & 0 & 0 \\
0 & 0 & 0 \\
0 & 0 & 0 \\
1 & 0 & 0 \\
\frac{1}{L_{f}} & 0 & 1 \\
0 & \frac{1}{L_{f}} & 0 \\
0 & 0 & \frac{1}{L_{f}}
\end{array}\right] \mathbf{E}=\left[\begin{array}{ccc}
-\frac{1}{C_{f}} & 0 & 0 \\
0 & -\frac{1}{C_{f}} & 0 \\
0 & 0 & -\frac{1}{C_{f}} \\
0 & 0 & 0 \\
0 & 0 & 0 \\
0 & 0 & 0
\end{array}\right] \\
\mathbf{C} & =\left[\begin{array}{llll}
1 & 0 & 0 & 0 \\
0 & 1 & 0 & 0
\end{array}\right] .
\end{aligned}
$$

The transfer function representation of equation (1) is obtained as:

$$
V_{\alpha \beta 0}(s)=G_{(3 \times 3)}(s) U_{\alpha \beta 0}(s)-Z_{(3 \times 3)}(s) I_{o \alpha \beta 0}(s)
$$




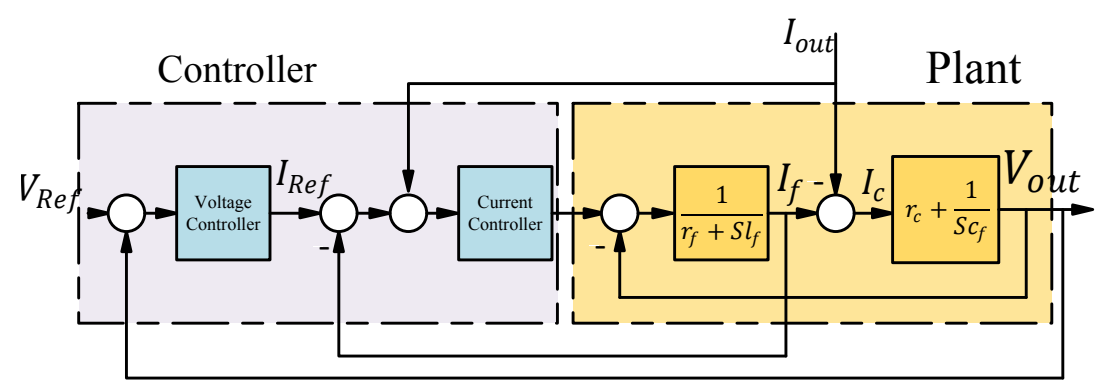

Figure 5. plant for voltage and current controller.

where $G_{(3 \times 3)}$ and $Z_{(3 \times 3)}(s)$ are:

$$
\begin{aligned}
& g_{12}(s)=g_{13}(s)=g_{21}(s)=g_{23}(s)=g_{31}(s)=g_{32}(s)= \\
& z_{12}(s)=z_{21}(s)=z_{21}(s)=z_{23}=(s) z_{31}(s)=z_{32}(s)=0 \\
& g_{11}(s)=g_{22}(s)=g_{33}(s)=\frac{1}{L_{f} C_{f} s^{2}+r_{f} C_{f} s+1} \\
& z_{11}(s)=z_{22}(s)=z_{33}(s)=\frac{L_{f} s+r_{f}}{L_{f} C_{f} s^{2}+r_{f} C_{f} s+1} .
\end{aligned}
$$

Equation (4) shows that the matrix transfer function of each DG control system is diagonal (completely decoupled) and can be regarded as three SISO control systems. Therefore, the problem of designing a three-inputs three-outputs control system, is reduced to design three one-input one-output systems.

\subsection{Operation Principles of the Proposed Control Strategy}

The single line diagram of the LV microgrid that is studied in this paper is shown in Fig. 1. The RMS of the phase-to-ground output voltage of DGs in this network is $220 \mathrm{~V}$. All DG units are interfaced to the microgrid through DC/AC converters. The dc-side of each inverter is equipped with multiple sources which consist of a dispatchable unit, such as micro-turbine, a non-dispatchable unit such as the photovoltaic cell, and a surge unit which supplies the system in severe transient conditions. Therefore, these three units provide almost a constant DC voltage for the inverter [56]. Therefore, the energy source of each DG unit is modeled by an ideal dc voltage source, and the dynamics of DC part of the inverter is not considered in this study.

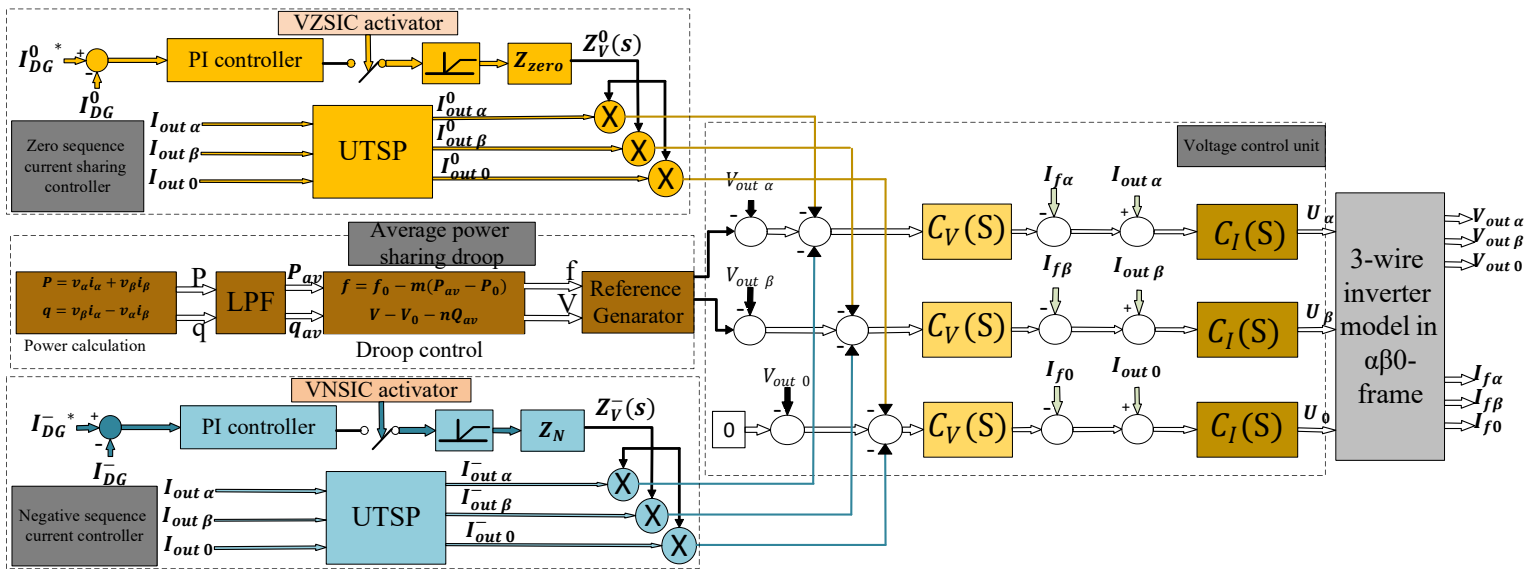

Figure 6. Control unit of DG units.

Controllers are designed in the stationary reference frame $(\alpha \beta 0)$ which is presented in [53]. It is noted that designing controllers is easier in the synchronous reference frame $(d q 0)$ than the stationary reference frame $(\alpha \beta 0)$. However, it should be noted that these controllers cannot effectively control a microgrid with unbalanced loads. The proposed control strategy of each unit consists of; 1) current 
Table 2. Controllers parameters.

\begin{tabular}{|c|c|c|}
\hline Parameter & $C_{I}$ & $C_{V}$ \\
\hline$C(s)$ & - & $g_{c}=3.7, z=60, p=8 e^{3}$ \\
\hline$K_{p}$ & 1 & 17.71 \\
$K_{I_{1}}$ & 600 & $5 e^{3}$ \\
$K_{I_{3}}$ & $1 e^{3}$ & $7 e^{3}$ \\
$K_{I_{5}}$ & $1.2 e^{3}$ & $4.5 e^{3}$ \\
$K_{I_{7}}$ & $1.6 e^{3}$ & $5 e^{3}$ \\
$K_{I_{9}}$ & $2.6 e^{3}$ & $10 e^{3}$ \\
$K_{I_{11}}$ & $2.8 e^{3}$ & $14 e^{3}$ \\
$K_{I_{13}}$ & - & $17 e^{3}$ \\
\hline$\omega_{0}$ & $2 \times 50 \times \pi$ & $2 \times 50 \times \pi$ \\
$\omega_{c}$ & $\pi$ & $\pi$ \\
\hline
\end{tabular}

controller; 2) voltage controller; 3) average power sharing controller, and 4) negative- and zero-sequence currents controller. The current and voltage controllers are proportional resonance (PR) controllers. In islanded microgrid, it is not necessary to use PR controller as the current controller since using a simple proportional controller would suffice. However, by using a PR controller as current controller, the proposed control strategy can be used both in islanded mode and grid-connected mode. Therefore, using this controller as the current controller can reduce the cost of design and operation of DG units, while the microgrid can smoothly switch between islanded and grid-connected modes.

Under unbalanced load condition, the instantaneous power has a double-frequency oscillatory term in addition to the DC power [57]. The conventional droop controller which is widely adopted to share average power component is not able to share the oscillatory power component among the DG units. In [51,58], a virtual negative-sequence impedance controller (VNSIC) was proposed to share the negative-sequence current. However, this approach has not been adopted for zero-sequence current sharing. In this paper, the same approach is adopted to share the zero-sequence current. By controlling the flow of negative- and zero-sequence currents of each DG unit, oscillatory part of the power of each unit is shared according to its capacity. The strategy for the compensation of zero- and negative-sequence currents is based on the compensating unbalanced loads by its upstream DG unit. Moreover, for loads with no upstream DG unit, the negative- and zero-sequence currents are shared by adjacent DG units. By deploying this strategy, the flow of negative- and zero-sequence currents in microgrid is minimized, and DG units compensate these currents according to their capacity. Hence, the overall power quality of the the microgrid is improved.

\subsection{Proportional Resonance Controller}

Because the matrix transfer function of the DG subsystem in (4) is diagonal, the three identical SISO controllers can be independently designed for the quadrature axes $\alpha, \beta$ and 0 . Fig. 5 shows the structure of the voltage and current controllers for the $\alpha, \beta$ and 0 axes. A good controller should be able to track the reference signal with minimum transient and error while it should guarantee a low THD of voltage in the presence of harmonic loads. Since the controllers are designed in the stationary framework, reference signals are sinusoidal. Therefore, the multi-proportional-resonant controller (MPRC) is used. MPRC can track sinusoidal references with zero tracking error, while conventional PI controller has magnitude and phase error and can not effectively track sinusoidal signals. Therefore, MPRC can handle harmonic loads without deteriorating voltage quality. By using MPRC as the current controller, the control structure can be used in the grid-connected mode of operation as well. Therefore, there is no need for a different control structure in grid-connected mode. As a result, the total cost for design and operation of microgrid decreases. Matlab SISO Tool software is used to design the controllers. The transfer function of MPRC is as follows: 


$$
\begin{array}{r}
C_{V} \text { and } C_{I}: C(s)\left[K_{p}+\sum K_{i_{h}} \frac{s}{s^{2}+2 h \omega_{c} s+\left(h \omega_{0}\right)^{2}}\right] \\
C(s)=g_{c} \frac{s+z}{s+p}
\end{array}
$$

Where $C(s)$ is a lead compensator that is added to the structure of the voltage controller to increase the phase margin and bandwidth of the system. Fig. 4 shows the Bode diagram of the voltage control loop system. As it is seen from this figure, the system has a good gain margin and a phase margin of 30 degrees while the bandwidth is about $1 \mathrm{kHz}$. Therefore, the controller shows a robust stability margin, and very fast response to load step changes. It also provides and excellent noise and harmonic rejection capability due to its high bandwidth. The coefficients of current and voltage controllers are given in Table 2.

\subsection{Proposed Control System}

Fig. 6 shows the block diagram of the proposed control system. The voltage controller consists of three identical MPRC whose reference signals are determined by the droop control strategy. The droop coefficients, i.e., $m, n$ are obtained according to the rated power of each DG and the maximum deviation of frequency and voltage [59]. The instantaneous real power is calculated using output current and voltage of each DG based on the instantaneous power theory that is proposed in [57]. The instantaneous power is passed through a low pass filter to attenuate the ripples that are caused by unbalanced and harmonic loads. The average power is then applied to the droop controller to determine the working frequency and the voltage magnitude of each DG unit. Then, the voltage and frequency are applied to the reference generator to produce a symmetrical three-phase reference voltage. Since the control structure is in the stationary frame, the Clark transformation is applied to the symmetrical voltage. Therefore, the zero parameters of the Clark transformation will always be zero since the reference voltage is always symmetrical. The output of voltage controller is the reference for the current controller and is compared with the current of the filter inductance. The resultant current is then feedforwarded to the output current which improves the system stability. The output of the current controller is then applied to the inverter.

To control the zero- and negative-sequence currents, zero- and negative-sequence current controllers are used, respectively. In these blocks, the output current of each DG unit $\left(I_{\alpha \beta 0}\right)$ is decomposed to its symmetrical component with a unified three-phase signal processor (UTSP) [60]. The UTSP block can accurately decompose the symmetrical parameters of current, so that, the instantaneous amount of zero- and negative-sequence currents can be obtained from the output current.

The extracted zero- and negative-sequence currents are multiplied by a resistive or inductive impedance gain, $Z_{V}^{-}$and $Z_{V}^{0}$ respectively to produce the references for zero- and negative-sequence voltages. These voltages are then added to the reference signals of the voltage controller. The values of $Z_{V}^{-}$and $Z_{V}^{0}$ are determined by the virtual negative-sequence impedance controller (VNSIC) and the virtual zero-sequence impedance controller (VZSIC). The virtual impedance blocks compare negativeand zero-sequences of each unit with its negative- or zero-sequence references. The resultant signal is then passed through a PI controller and then multiplied by a resistive or inductive impedance to generate the reference for the virtual impedance of zero- or negative-sequence impedances of each DG unit.

\subsubsection{Positive-, Negative- and zero-sequence Models of DG Units}

To accurately control a DG unit, the dynamic model of Fig. 6 can be divided into positive-, negative- and zero-sequence elements. In [58], dynamic model of the system is divided into positive 
and negative elements. The same procedure can be adopted to extract the zero-sequence dynamic model. In Fig. 6 , the voltage of the closed-loop system in the $\alpha \beta 0$-frame can be expressed as:

$$
\begin{array}{r}
V_{\alpha, \beta, 0}(s)=H(s)\left[V_{\alpha, \beta, 0}^{*}(s)-Z_{V}^{-}(s) I_{o_{\alpha, \beta, 0}}^{-}(s)\right. \\
\left.-Z_{V}^{0}(s) I_{\alpha_{\alpha, \beta, 0}}^{0}(s)\right]-Z_{\text {out }}(s) I_{o_{\alpha, \beta, 0}}(s)
\end{array}
$$

where $V_{\alpha, \beta, 0}$ and $I_{\alpha_{\alpha, \beta}, 0}$ are the voltage reference signal and the DG terminal current, respectively. $H(s)$ denotes the closed-loop transfer function from the reference signal to the output voltage, while $Z_{\text {out }}(s)$ is the output impedance. $I_{\alpha_{\alpha, \beta, 0}}^{-}$and $I_{o_{\alpha, \beta}, 0}^{0}$ are the instantaneous negative and zero-sequence components of $I_{o_{\alpha, \beta, 0}} \cdot Z_{V}^{-}(s)$ and $Z_{V}^{0}(s)$ are the virtual impedances that are determined by the VNSIC and the VZSIC, respectively. The virtual impedance can be inductive or resistive or a combination of both [58]. Equation (6) can be rewritten as:

$$
\begin{array}{r}
V_{\alpha, \beta 0}^{+}(s)+V_{\alpha, \beta, 0}^{-}(s)+V_{\alpha, \beta, 0}^{0}(s)=H(s) V_{\alpha, \beta, 0}^{*}(s) \\
-Z_{\text {out }}(s) I_{o_{\alpha, \beta}, 0}^{+}(s)-\left[Z_{V}^{-}(s) H(s)+Z_{\text {out }}(s)\right] I_{\alpha_{\alpha, \beta}}^{-}(s) \\
-\left[Z_{V}^{0}(s) H(s)+Z_{\text {out }}(s)\right] I_{\alpha_{\alpha, \beta, 0}}^{0}(s) .
\end{array}
$$

Equation (7) can be divided into positive- , negative- and zero-sequence voltages. Therefore, the output voltage of DG unit can be expressed as:

$$
\left\{\begin{array}{c}
V_{\alpha, \beta, 0}^{+}(s)=H(s) V_{\alpha, \beta, 0}^{*}(s)-Z_{\text {out }}(s) I_{o_{\alpha, \beta, 0}}^{+}(s) \\
V_{\alpha, \beta, 0}^{-}(s)=-\left[Z_{V}^{-}(s) H(s)+Z_{\text {out }}(s)\right] I_{\alpha_{\alpha, \beta, 0}}^{-}(s) \\
V_{\alpha, \beta, 0}^{0}(s)=-\left[Z_{V}^{0}(s) H(s)+Z_{\text {out }}(s)\right] I_{o_{\alpha, \beta, 0}}^{0}(s) .
\end{array}\right.
$$

In the working condition of microgrid $H\left(\vec{j} \omega_{0}\right)=1 \angle 0$. In this paper the virtual impedances $Z_{V}^{-}$ and $Z_{V}^{0}$ are chosen to be inductive. Therefore, the negative-sequence impedance of each DG unit at the system frequency is:

$$
\begin{aligned}
& Z_{\text {out }}^{-}\left(j \omega_{0}\right)=Z_{V}^{-}\left(j \omega_{0}\right)+Z_{\text {out }}\left(j \omega_{0}\right) \\
= & R_{\text {out }}\left(\omega_{0}\right)+j\left[X_{\text {out }}\left(\omega_{0}\right)+X_{V}^{-}\left(\omega_{0}\right)\right]
\end{aligned}
$$

Moreover, the zero-sequence impedance at the system frequency is:

$$
\begin{aligned}
& Z_{\text {out }}^{0}\left(j \omega_{0}\right)=Z_{V}^{-}\left(j \omega_{0}\right)+Z_{\text {out }}\left(j \omega_{0}\right) \\
= & R_{\text {out }}\left(\omega_{0}\right)+j\left[X_{\text {out }}\left(\omega_{0}\right)+X_{V}^{0}\left(\omega_{0}\right)\right]
\end{aligned}
$$

To control the negative- and zero-sequence voltages that are injected to the reference of the voltage controller, the $X_{V}^{-}$and $X_{V}^{0}$ can be changed. The values of these parameters are set by the VNSIC and the VZSIC of each unit. The negative- and zero-sequence voltages are then injected to the reference of the voltage controller. Therefore, by controlling the negative- and zero-sequence voltages of each unit, the negative- and zero-sequence output currents of each unit are controlled. The maximum permissible values for $X_{V}^{-}\left(\omega_{0}\right)$ and $X_{V}^{-}\left(\omega_{0}\right)$ can be calculated based on the IEEE standards [14,61]. Negative- and zero-sequence unbalanced factors are equal to: 


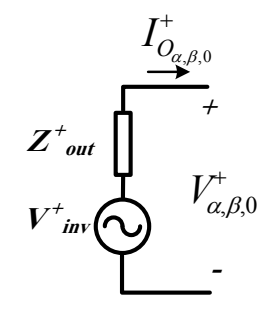

(a)

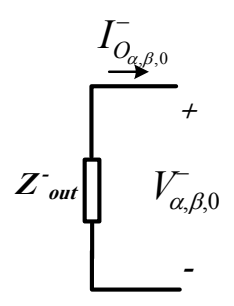

(b)

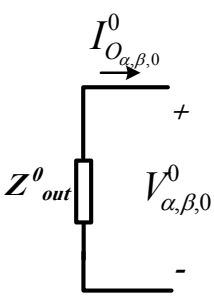

(c)

Figure 7. (a) Positive-, (b) negative- and (c)zero-sequence models of the DG unit.

$$
\begin{aligned}
& (V U F)^{-}=\frac{V_{\alpha, \beta, 0}^{-}}{V_{\alpha, \beta, 0}^{+}}=\frac{Z_{\text {out }}^{-} I_{o_{\alpha, \beta}, 0}^{-}}{V_{\alpha, \beta, 0}^{+}}<0.02 \\
& (V U F)^{0}=\frac{V_{\alpha, \beta, 0}^{0}}{V_{\alpha, \beta, 0}^{+}}=\frac{Z_{\text {out }}^{0} I_{\alpha_{\alpha, \beta}, 0}^{0}}{V_{\alpha, \beta, 0}^{+}}<0.02
\end{aligned}
$$

Another limiting factor associated with the injection of the negative- and zero-sequence currents is the capability of each unit to inject these currents. Therefore, the capacity of each unit and the inequality constraint in(11) determine the maximum value of the negative- and zero-sequence output impedances. Based on (8), the positive-, negative-, and zero-sequence models for each DG unit are obtained and is shown in Fig. 7.

\subsubsection{Negative- and zero-sequence Currents Sharing Strategy}

In the previous Section, the technical procedure for controlling negative- and zero-sequence currents was explained. In this Section, the zero- and negative-sequence current sharing strategy is proposed so that it minimizes the flow of the unbalanced current throughout the LV microgrid. Therefore, the overall power quality of microgrid improves. With the use of an accurate power-sharing strategy, not only the overall power quality of microgrid is improved, but also the proper autonomous operation of the microgrid is guaranteed. In this strategy, the unbalanced current of each load is compensated by its upstream unit. However, the unbalanced currents of loads with no upstream unit are shared by its adjacent units. Considering these two conditions, the reference for negative- and zero-sequence currents of each unit must be as follows:

$$
\begin{aligned}
& I_{D G}^{-}{ }^{*}=\sqrt{{I_{\text {loc }}}^{2}+{I_{\text {nonloc }}}^{* 2}+2 I_{\text {loc }}^{-} I_{\text {nonloc }}^{-}{ }^{*} \cos \theta_{-}} \\
& I_{D G}^{0}{ }^{*}=\sqrt{{I_{\text {loc }}^{0}}^{2}+I_{\text {nonloc }}^{0}{ }^{* 2}+2 I_{\text {loc }}^{0} I_{\text {nonloc }}^{0}{ }^{*} \cos \theta_{0}}
\end{aligned}
$$

Where $I_{l o c}^{-}$and $I_{l o c}^{0}$ are magnitudes of the negative- and zero-sequence currents of the local loads, respectively. $\theta_{-}$and $\theta_{0}$ are the phase difference between $I_{l o c}$ and $I_{n o n l o c}{ }^{*}$ for the negative- and zero-sequence currents, respectively.

$I_{\text {nonloc }}^{-}{ }^{*}$ and $I_{\text {nonloc }}^{0}{ }^{*}$ are defined as:

$$
I_{\text {nonloc }}^{-}{ }^{*}=\frac{I_{\text {max }_{D G i}}^{-}}{\sum I_{\text {max }_{D G i}}^{-}} I_{\text {nonloc }}^{-} I_{\text {nonloc }}^{0}{ }^{*}=\frac{I_{\text {max }_{D G i}}^{0}}{\sum I_{\text {max }_{D G i}}^{0}} I_{\text {nonloc }}^{0}
$$

In (13), $I_{\max _{D G i}}^{-}$and $I_{\max _{D G i}}^{0}$ are respectively the maximum negative- and zero-sequence currents that the $i^{\text {th }} \mathrm{DG}$ can inject. $I_{\text {nonloc }}^{-}$and $I_{\text {nonloc }}^{0}$ are the amplitudes of the negative- and zero-sequence of feeders supplying the nonlocal load. Referring to (13) and (12), the local unbalanced loads are 
Table 3. MG system parameters.

\begin{tabular}{|c|c|c|}
\hline \hline Parameter & Value & Comments \\
\hline$S_{\text {base }}$ & $300 \mathrm{kVA}$ & DG ratings \\
\hline$Z_{\text {line } 1}$ & $0.04+\mathrm{j} 0.0157$ p.u. & $0.8 \mathrm{~km}$ overhead line \\
$Z_{\text {line } 2}$ & $0.07+\mathrm{j} 0.0332$ p.u. & $1.3 \mathrm{~km}$ overhead line \\
$Z_{\text {line3 }}$ & $0.01+\mathrm{j} 0.0022$ p.u. & $0.2 \mathrm{~km}$ overhead line \\
\hline$L_{f 1}, L_{f 2}$ & $0.3 \mathrm{mH}$ & series filter inductance \\
$r_{f 1}, r_{f 2}$ & $0.0015 \Omega$ & series filter resistance \\
$C_{f 1}, C_{f 2}$ & $2200 \mu \mathrm{F}$ & filter capacitance \\
$V_{d c}$ & $1500 \mathrm{~V}$ & dc bus voltage \\
$f_{s}$ & $6 \mathrm{kHz}$ & switching frequency \\
$P_{D G_{1}, 2}, P_{D G_{2}}$ & $100 \mathrm{KW}$ & maximum real power \\
$Q_{D G_{1}}, Q_{D G_{2}}$ & $100 \mathrm{kVAr}$ & maximum reactive power \\
$m_{D G_{1}}, m_{D G_{2}}$ & $3.33 \mathrm{~Hz} / \mathrm{MW}$ & P-f droop coefficients \\
$n_{D G_{1}}, n_{D G_{2}}$ & $3.26 \mathrm{~V} / \mathrm{MVAr}$ & Q-V droop coefficients \\
\hline$I_{\text {max }_{D G_{1}}}, I_{m a x_{D G_{2}}}$ & $97 \mathrm{~A}(0.13 \mathrm{p} . \mathrm{u})$. & \\
$I_{\text {max }_{D G_{1}}}, I_{\text {max }_{D G_{2}}}$ & $97 \mathrm{~A}(0.13 \mathrm{p} . \mathrm{u})$. & \\
\hline$k_{P n_{1}}, k_{I n_{1}}$ & $3 e^{-6}, 1 e^{3}$ & VNSIC parameters of $D G_{1}$ \\
$k_{P n_{2}}, k_{I n_{2}}$ & $3 e^{-6}, 1 e^{3}$ & VNSIC parameters of $D G_{2}$ \\
\hline$k_{P z_{1}}, k_{I z_{1}}$ & $1 e^{-6}, 2 e^{3}$ & VZSIC parameters of $D G_{1}$ \\
$k_{P z_{2}}, k_{I z_{2}}$ & $1 e^{-6}, 2 e^{3}$ & VZSIC parameters of $D G_{2}$ \\
\hline
\end{tabular}

compensated locally while the unbalanced loads with no upstream DG unit are shared among all DG units according to their unbalanced load capacity. By using $\mathrm{PMU}^{1}$ which is installed on feeders, the phase difference between local and nonlocal currents is calculated. If all impedances of lines are known, the PMU unit can be omitted. Since the impedances of lines are usually unknown, with the help of PMU unit, an accurate power sharing can be achieved. This method has an advantage over other power sharing method that only considers amplitude of unbalanced currents as it considers both amplitude and phasor of unbalanced currents. For example, in some scenarios, the unbalanced currents of some loads can nullify those of other loads, while the DG unit remains under balanced condition. So if the phasor of currents is not considered, the reference currents for virtual impedance loop will not be accurate. In the proposed control strategy, the VNSIC and VZSIC are enabled when: 1) The DG unit reaches to its maximum capacity so that it is not able to inject the required negative and zero sequence currents. When the VNSIC and the VZSIC are disabled, the virtual impedances of the unit are kept at the minimum value, i.e., $X_{V}^{-}=X_{V}^{0}=0$. This means that the DG unit compensates all unbalanced loads in its downstream. When a DG unit reaches to its maximum capacity, $X_{V}^{-}$and $X_{V}^{0}$ are changed to prevent the unit from overloading. 2) The control system of the DG unit detects unbalanced current flow from adjacent feeders. Therefore, the DG units change their virtual impedances accordingly to share the remaining unbalanced currents. Otherwise, the VNSIC and VZSIC are disabled, and the negative- and zero-sequence of the output impedances are kept constant at the minimum value. When VNSIC and VZSIC are activated, the PI controllers set $Z_{V}^{0}$ and $Z_{V}^{-}$to a desirable value.

\section{Results and Discussion}

To verify the effectiveness of the proposed control strategy, the LV microgrid showed in Fig. 1 has been simulated in PSCAD/EMTDC environment. The LV microgrid is assumed to operate in islanded mode and comprises a three-feeder distribution system with two electronically-coupled four-wire dispatchable DG units. All DG units are equipped with the PR controller, droop control strategy, VNSIC, and VZSIC. The parameters of microgrid including all DG units are given in Tables 2 and 3. Several load changes are introduced to the microgrid aiming to verify its dynamic performance.

1 phasor measurement unit 


\subsection{Case study I}
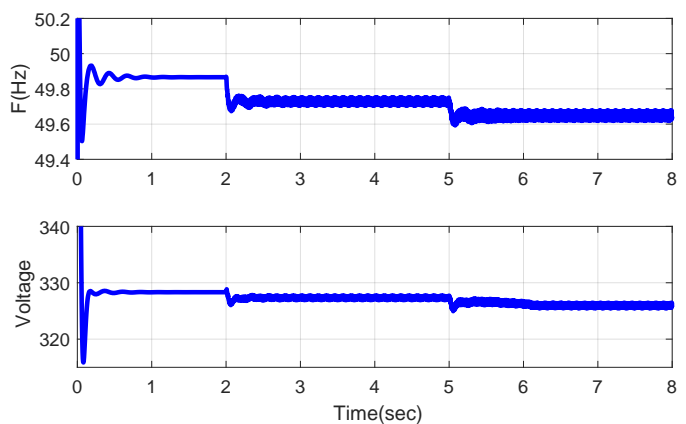

Figure 8. Instantaneous voltage and frequency at the DG terminal of feeder $F_{1}$.

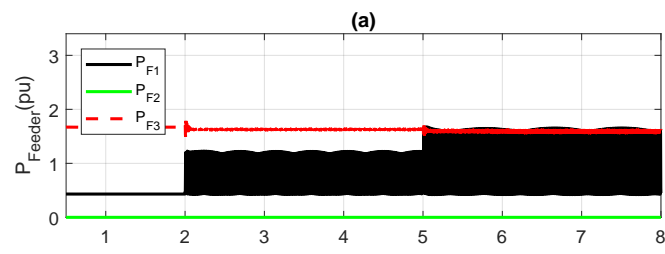

(b)

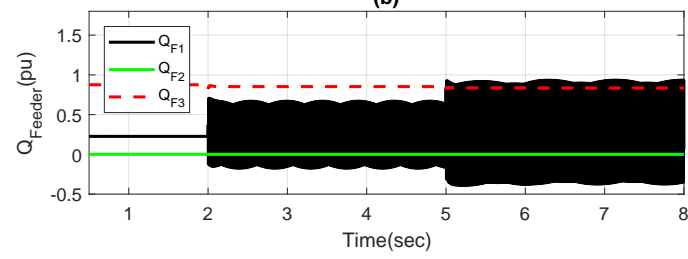

Figure 9. Active and Reactive power of feeders.

In this case study, initially, two balanced loads are connected to feeders $F_{1}$ and $F_{3}$. The load that is connected to feeder $F_{3}$ is a three-phase $R L$ load with the nominal power of $285 \mathrm{kVA}$ and a power factor of $P F=0.88$, while the load connected to feeder $F_{1}$ is a three-phase $R L$ load with $75 \mathrm{kVA}$ with $P F=0.9$. A single-phase load rated $40 \mathrm{kVA}$ with $P F=0.98$ is connected to one phase of feeder $F_{1}$ at $t=2 \mathrm{~s}$. Subsequent to this load change, at $t=5 \mathrm{~s}$, another single-phase load rated $26 \mathrm{kVA}$ with $P F=0.95$ is connected to the same phase of feeder $F_{1}$. The instantaneous real and reactive powers considering these load changes are shown in Fig. 9. Since feeder $F_{1}$ becomes unbalanced, a double-frequency ripple appears on the instantaneous power components of this feeder. As it is observed, the double-frequency ripple amplitude increases as another unbalanced load is connected to the feeder $F_{1}$ at $t=5 \mathrm{~s}$. Fig. 10 shows the positive-, negative- and zero-sequence current components of feeder $F_{1}$ that increases at $t=2 \mathrm{~s}$ and $t=5 \mathrm{~s}$.

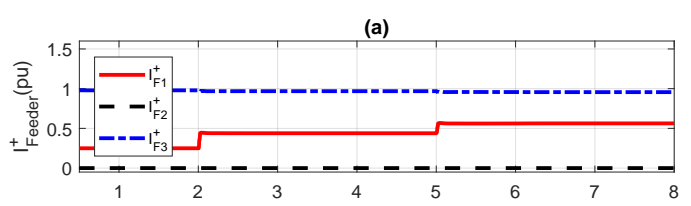

(b)

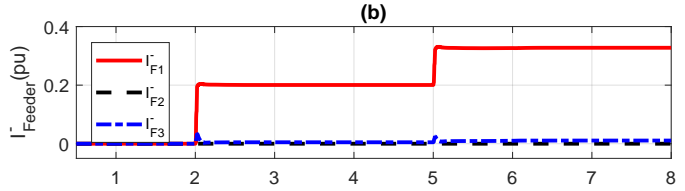

(c)

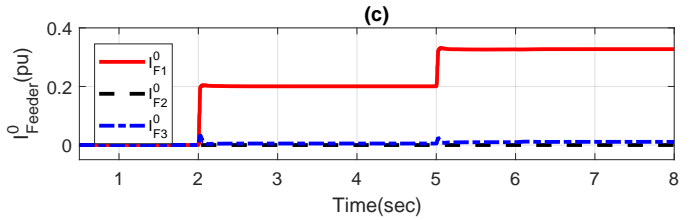

Figure 10. (a) Positive-, (b) negative- and (c) zero-sequence currents of the feeders.

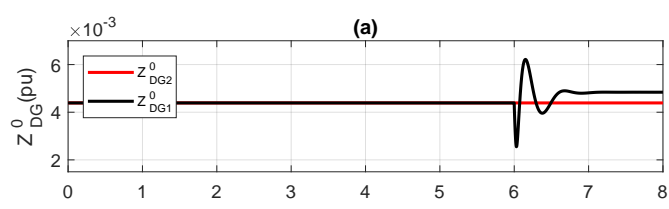

(b)

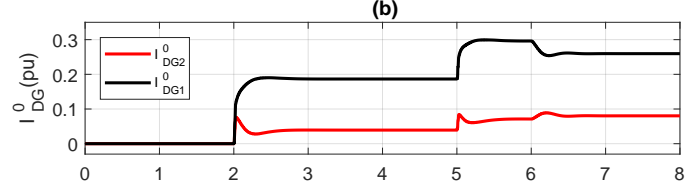

(b)

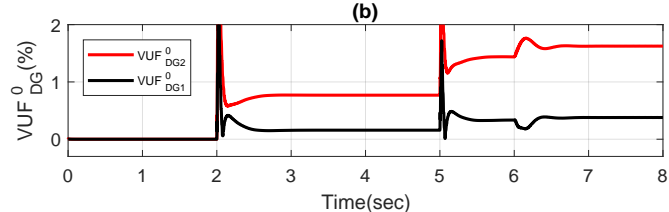

Figure 11. Zero-sequence (a) output impedance, (b) current, and (c) VUF of DG units.

The first step toward controlling power component effectively is controlling Active and reactive powers. If these components are not controlled accurately, it will not be possible to share other power components effectively. Fig. 13 shows instantaneous real and reactive power components of DG units. Before the $t=2 \mathrm{~s}$, all loads in the system are balanced. The rating power of both DGs is the same. Therefore, their share of active and reactive power is the same. Fig. 13 (a) shows the active power 
output of DG units. As it seems, both units provide the exact amount of active power. Fig. 13 (b) shows the reactive power output of DG units. The reactive power sharing in LV networks is not as accurate as active power component. Since the ratio of reactance to inductance in an LV network is high, usually active and reactive power components are not decoupled effectively. However, the accuracy of reactive power sharing is quite acceptable for this research which its goal is demonstrating unbalanced current sharing in LV networks. Fig. 8 (a) shows the frequency of the system. The droop coefficient is set so that on the no-load situation, the frequency stays at $50 \mathrm{~Hz}$. with the use of conventional droop with a dynamic coefficient, the voltage and frequency reach stable mode after about 0.5 seconds of transient time. Fig. 8 (b) shows the voltage output the at DG1 terminal. After addition of unbalanced load to the loads, a double frequency ripple is added to frequency and voltage of the network. The frequency and voltage deviation is less than 1 and 5 percent for frequency and voltage respectively. Which demonstrate that the deviation is in the range of acceptable limit for frequency and voltage. Figs. 11(a) and (b) show the zero-sequence output impedances and the zero-sequence currents of the DGs, respectively. As it was mentioned earlier, the primary aim of the unbalanced current sharing strategy is to compensate zero- and negative-sequence currents locally. However, if the maximum capacity of a unit to compensate unbalanced currents is reached, other units inject the remaining unbalanced current. Prior to $t=5 \mathrm{~s}$, the VZSIC and VNSIC of the DG units are not activated, and virtual impedances are kept at the minimum value. Fig. 11 (b) shows that almost all zero-sequence current of the unbalanced load is compensated by unit 1 . However, when another unbalanced load is added to feeder $F 1$ at $t=5 \mathrm{~s}$, the maximum capacity of the adjacent unit (DG1) is reached, and the remaining unbalanced current is then provided by the other unit (DG2). This operation is done by increasing the zero-sequence virtual impedance of unit 1 when the VZSIC of unit 1 detects that the maximum capacity of the unit is reached.

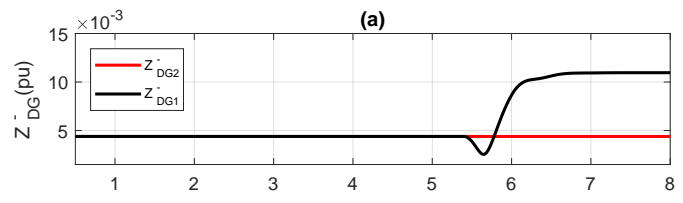

(b)

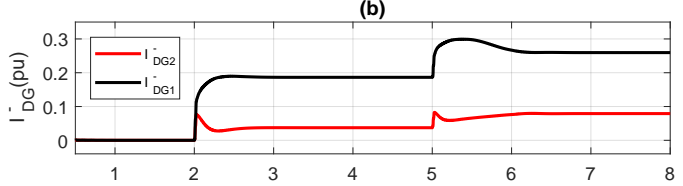

(c)

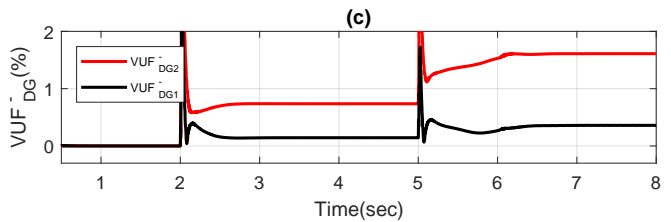

Figure 12. Negative-sequence (a) output impedance, (b) current, and (c) VUF of DG units.

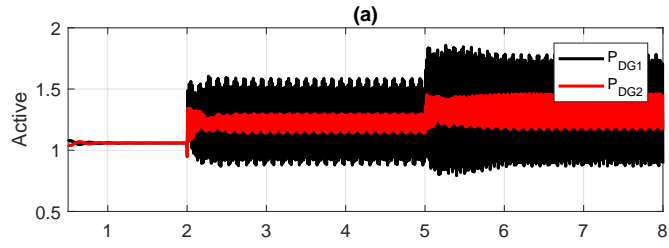

(b)

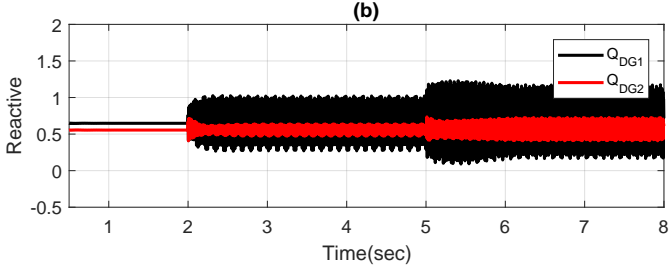

Figure 13. Dynamic response of DG units to unbalanced load changes in feeder $F_{1}$ : (a) real power, and (b) reactive power components of DG units.

Figs. 12 (a) and (b) show the negative-sequence output impedance and the negative-sequence currents of the DGs, respectively. The same scenario happens for negative-sequence current when the maximum capacity of unit 1 for providing negative-sequence current is reached, and the remaining negative-sequence current is shared by another unit through the activation of VNSIC. Fig. 11(C) and Fig. 12(C) show, respectively, the voltage unbalanced factor (VUF) for the zero- and negative-sequence voltage of DG units during load changes. The VUF of DG1 is always under 2 percent for zero- and negative-sequences while DG1 is injecting the maximum value of zero- and negative-sequence currents. Fig. 13 shows instantaneous real and reactive power components of DG units. The magnitude of 


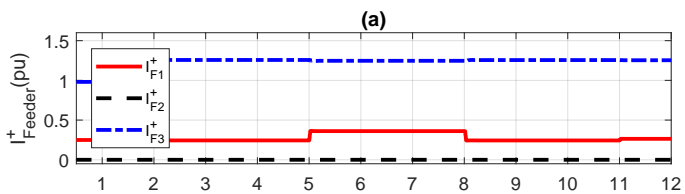

(b)

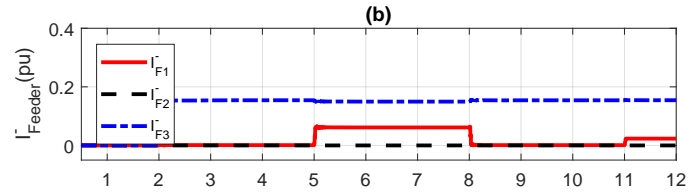

(c)

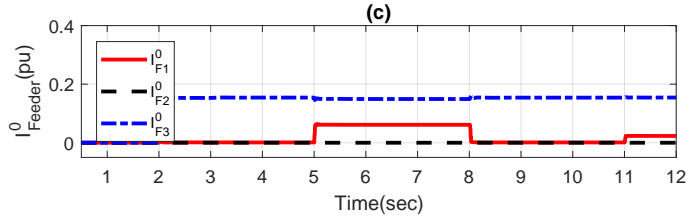

Figure 16. (a) positive and (b) negative, and (c) zero-sequence currents of the feeders.

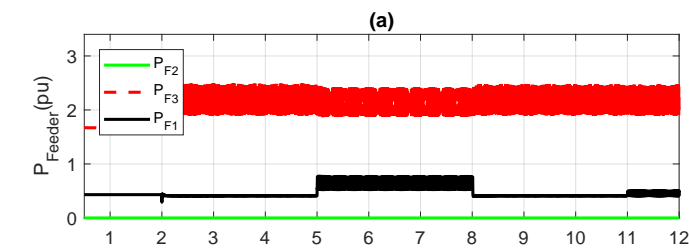

(b)

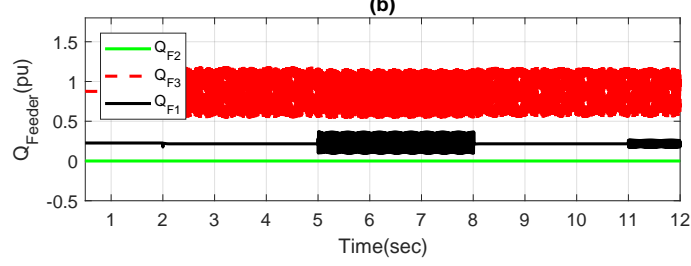

Figure 15. Unbalanced load changes in feeders $F_{3}$ and $F_{2}$ (a) instantaneous real and (b) reactive power of feeders.

(a)
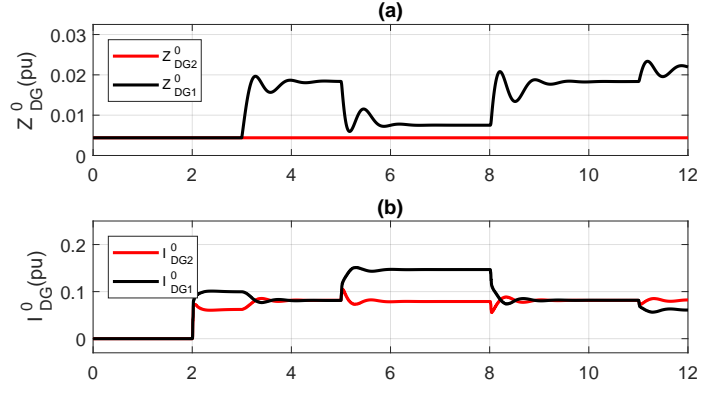

(b)

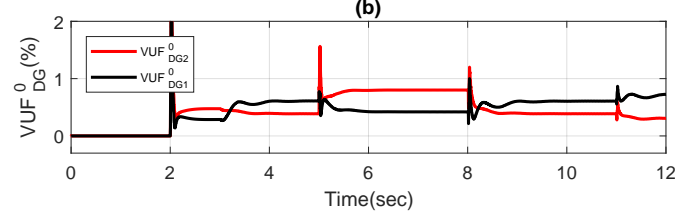

Figure 17. Zero-sequence (a) output impedance, (b) current, and (c) VUF of DG units. 
Fig. 17(a) and Fig. 18(a) show the zero- and negative-sequence virtual impedances of DG units. After the connection of the unbalanced loads to feeder $F 3$ at $t=2 \mathrm{~s}$, the VZSIC and VNSIC are activated at $t=2.4 \mathrm{~s}$. While VZSIC and VNSIC are not activated, the unbalanced load sharing is performed according to the line impedances. Fig. 17(b) and Fig. 18(b) show the zero- and the negative-sequence current components of the DG units, respectively. Having activated the VZSIC and VNSIC of DG1, the unbalanced current of feeder F3 is shared between DG units according to their negative- and zero-sequence capacities that are considered to be equal for units. Therefore, negative- and the zero-sequence current components of units become equal. When the unbalanced load is connected to feeder $F 1$ at $t=5 \mathrm{~s}$, it should be compensated by unit 1 according to the proposed strategy. Therefore, $D G 1$ decreases its $Z_{V}^{-}$and $Z_{V}^{0}$. As it can be seen from Fig. 17(b) and Fig. 18(b), the unbalanced load current flowing through feeder $F 1$ at $t=5 \mathrm{~s}$ is completely compensated by $D G 1$ while the portion of unbalanced current injected by $D G 2$ is kept intact. At $t=8 \mathrm{~s}$, the unbalanced load is disconnected from feeder F1. Therefore, VZSIC and VNSIC units of DG1 increase $Z_{V}^{-}$and $Z_{V}^{0}$ so that the unbalanced current portion of units become equal. At $t=11 \mathrm{~s}$, a single-phase load is connected to the phase $a$ of feeder $F 1$. However, this load compensates a portion of the unbalanced load connected to the phase $b$ and $c$ of Feeder F3. Therefore, the portion of the unbalanced current supplied by DG1 is decreased. The VZSIC and VNSIC increase the virtual impedances to accommodate this situation. If the amplitude of unbalanced current had been only considered ignoring its phase, the calculation of $I_{D G}^{-}{ }^{*}$ and $I_{D G}^{0}{ }^{*}$ would have been incorrect causing inaccurate current sharing. Fig. 17(c) and Fig. 18(c) show the voltage unbalanced factor for zero- and negative-sequence voltages. Throughout the simulation time, $V U F$ has a good condition and is always kept under 2 percent.

(a)

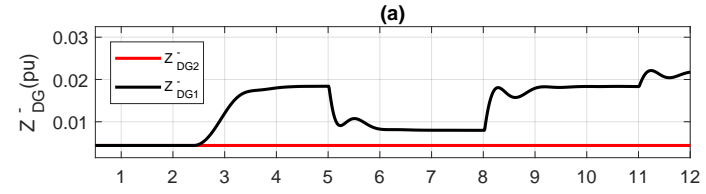

(b)

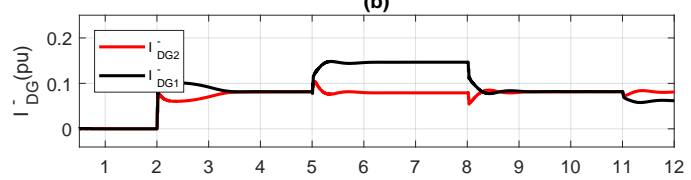

(b)

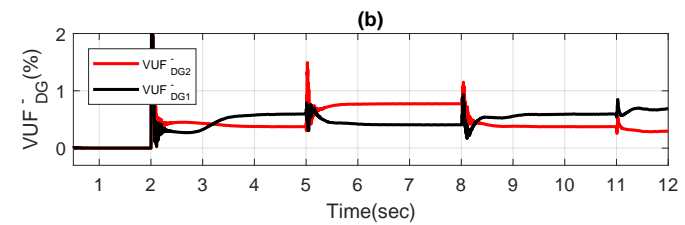

Figure 18. Negative-sequence (a) output impedance, (b) current, and (c) VUF of DG units.

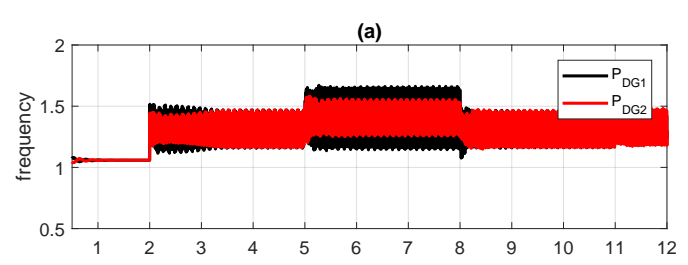

(b)

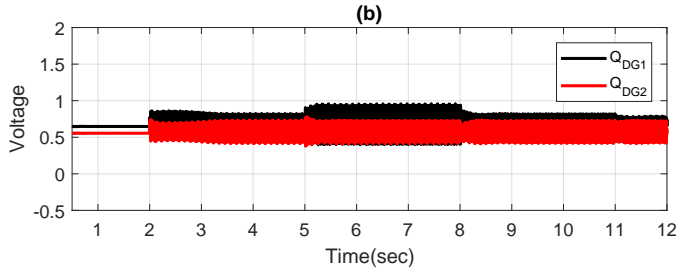

Figure 19. Dynamic response of DG units to unbalanced load changes in feeder $F_{1}$ and $F_{3}$ : (a) real power, and (b) reactive power components of DG units.

Fig. 19 shows the output powers of DG units. The double-frequency ripple on the output powers stems from the unbalanced power. When the unbalanced load is connected to the feeder $F 3$, the $100 \mathrm{~Hz}$ frequency ripple appears in the output power. After $t=5 \mathrm{~s}$, the portion of the unbalanced power for $D G 1$ increases while the portion of DG2 does not change. The unbalanced quota of units become equal after $t=8 \mathrm{~s}$. It shows that the control strategy has managed to share the unbalanced power in the microgrid with excellent accuracy.

\section{Conclusion}

A comprehensive strategy was presented for sharing unbalanced current in an islanded LV microgrid consisting of dispatchable units. In the proposed method, the zero- and negative-sequence currents are shared based on a novel strategy that decreases the flow of unbalanced current 
in the microgrid improving the overall power quality. In the proposed strategy, the zero- and negative-sequence currents of nonlocal loads are completely compensated by their associated DG units. However, if the capacity of a unit is not enough to offset the zero- and/or negative-sequence current terms or the unbalanced load has no upstream unit, the unbalanced current is shared among adjacent units. The proposed control strategy comprises a PR controller, a droop controller, a virtual negative-sequence impedance controller (VNSIC) and a virtual zero-sequence impedance controller (VZSIC). With VNSIC and VZSIC, the DG units can effectively share the negative- and zero-sequence currents. The performance of the proposed control strategy was evaluated by using digital time-domain simulation studies in PSCAD/EMTDC software. From the simulation results, we found that the proposed control strategy can

- control voltage and frequency while maintaining them within their allowable limits,

- share the average power among DG units, and

- effectively compensates the zero- and negative-sequence currents of unbalanced loads in a four-wired LV microgrid so that the power quality of the overall microgrid is improved.

Author Contributions: Conceptualization, F.N. and M.F.; Methodology, F.N. and M.F.; Software, F.N.; Validation, F.N.; Formal Analysis, F.N.; Investigation, F.N.; Resources, M.F.; Data Curation, F.N.; Writing-Original Draft Preparation, F.N. and M.F.; Writing-Review \& Editing, F.N. and M.F.; Visualization, F.N.; Supervision, M.F.; Project Administration, M.F.; Funding Acquisition, M.F.

Funding: This research was partly funded by grants from the Ulupono Initiative and Blue Planet Foundation.

Conflicts of Interest: The authors declare no conflict of interest. The funding sponsors had no role in the design of the study; in the collection, analyses, or interpretation of data; in the writing of the manuscript, and in the decision to publish the results.

\section{Abbreviations}

The following abbreviations are used in this manuscript:

MDPI Multidisciplinary Digital Publishing Institute

DOAJ Directory of open access journals

TLA Three letter acronym

LD linear dichroism

1. Lasseter, R.; Akhil, A.; Marnay, C.; Stephens, J.; Dagle, J.; Guttromson, R.; Meliopoulous, A.S.; Yinger, R.; Eto, J. Integration of distributed energy resources. The CERTS Microgrid Concept 2002.

2. Coujard, C.; Rodriguez, R.; Bollen, M.; Grenard, S. Innovative training techniques to account for power quality issues when deploying distributed energy resources. 2007 9th International Conference on Electrical Power Quality and Utilisation, EPQU 2007, pp. 1-6. doi:10.1109/EPQU.2007.4424157.

3. Li, B.; Roche, R.; Miraoui, A. Microgrid sizing with combined evolutionary algorithm and MILP unit commitment. Applied Energy 2017, 188, 547-562. doi:10.1016/j.apenergy.2016.12.038.

4. Moradi, M.H.; Foroutan, V.B.; Abedini, M. Power flow analysis in islanded Micro-Grids via modeling different operational modes of DGs: A review and a new approach. Renewable and Sustainable Energy Reviews 2017, 69, 248-262. doi:10.1016/j.rser.2016.11.156.

5. Abdelaziz, M.M.; El-Saadany, E. Maximum loadability consideration in droop-controlled islanded microgrids optimal power flow. Electric Power Systems Research 2014, 106, 168-179. doi:10.1016/j.epsr.2013.08.020.

6. Caramia, P.; Carpinelli, G.; Mottola, F.; Russo, G. An optimal control of distributed energy resources to improve the power quality and to reduce energy costs of a hybrid AC-DC microgrid. IEEE 2016, pp. 1-7.

7. Mehrasa, M.; Pouresmaeil, E.; Jørgensen, B.N.; Catalão, J.P. A control plan for the stable operation of microgrids during grid-connected and islanded modes. Electric Power Systems Research 2015, 129, $10-22$.

8. Mehrasa, M.; Pouresmaeil, E.; Mehrjerdi, H.; Jørgensen, B.N.; Catalão, J.P. Control technique for enhancing the stable operation of distributed generation units within a microgrid. Energy Conversion and Management 2015, 97, 362-373. 
9. Shahnia, F.; Chandrasena, R.P.S. A three-phase community microgrid comprised of single-phase energy resources with an uneven scattering amongst phases. International Journal of Electrical Power and Energy Systems 2017, 84, 267-283. doi:10.1016/j.ijepes.2016.06.010.

10. Palizban, O.; Kauhaniemi, K.; Guerrero, J.M. Microgrids in active network management-Part I: Hierarchical control, energy storage, virtual power plants, and market participation. Renewable and Sustainable Energy Reviews 2014, 36, 428-439. doi:10.1016/j.rser.2014.01.016.

11. Hochgraf, C.; Lasseter, R.H. Statcom controls for operation with unbalanced voltages. IEEE Transactions on Power Delivery 1998, 13, 538-544. doi:10.1109/61.660926.

12. Pati2012. Unbalanced Load Compensation 2012. 1, 74-80.

13. Sun, Q.; Zhou, J.; Guerrero, J.M.; Zhang, H. Hybrid Three-Phase/Single-Phase Microgrid Architecture With Power Management Capabilities. IEEE Transactions on Power Electronics 2015, 30, 5964-5977. doi:10.1109/TPEL.2014.2379925.

14. Smith, J.C.; Hensley, G.; Ray, L. IEEE Recommended Practice for Monitoring Electric Power Quality. IEEE Std 1995, pp. 1159-1995.

15. Mehrasa, M.; Pouresmaeil, E.; Jørgensen, B.N.; Catalão, J.P.S. A control plan for the stable operation of microgrids during grid-connected and islanded modes. Electric Power Systems Research 2015, 129, 10-22. doi:10.1016/j.epsr.2015.07.004.

16. Savaghebi, M.; Jalilian, A.; Vasquez, J.C.; Guerrero, J.M. Secondary Control for Voltage Quality Enhancement in Microgrids. IEEE Transactions on Smart Grid 2012, 3, 1893-1902. doi:10.1109/TSG.2012.2205281.

17. Delghavi, M.B.; Yazdani, A. Islanded-mode control of electronically coupled distributed-resource units under unbalanced and nonlinear load conditions. IEEE Transactions on Power Delivery 2011, 26, 661-673.

18. Quan, X.; Dou, X.; Wu, Z.; Hu, M.; Yuan, J. Harmonic voltage resonant compensation control of a three-phase inverter for battery energy storage systems applied in isolated microgrid. Electric Power Systems Research 2016, 131, 205-217. doi:10.1016/j.epsr.2015.10.010.

19. Saim, A.; Mellah, R.; Houari, A.; Machmoum, M.; Djerioui, A. Adaptive resonant based multi-loop control strategy for parallel distributed generation units in standalone microgrid application. Electric Power Systems Research 2017, 143, 262-271. doi:10.1016/j.epsr.2016.10.010.

20. Abdelaziz, M.M.A.; El-Saadany, E.F. Economic droop parameter selection for autonomous microgrids including wind turbines. Renewable Energy 2015, 82, 108-113. doi:10.1016/j.renene.2014.09.024.

21. Li, J.; Xiong, R.; Yang, Q.; Liang, F.; Zhang, M.; Yuan, W. Design/test of a hybrid energy storage system for primary frequency control using a dynamic droop method in an isolated microgrid power system. Applied Energy 2016. doi:10.1016/j.apenergy.2016.10.066.

22. Oureilidis, K.O.; Demoulias, C.S. A decentralized impedance-based adaptive droop method for power loss reduction in a converter-dominated islanded microgrid. Sustainable Energy, Grids and Networks 2016, 5, 39-49. doi:10.1016/j.segan.2015.11.003.

23. Rezaei, M.M.; Soltani, J. A robust control strategy for a grid-connected multi-bus microgrid under unbalanced load conditions. International Journal of Electrical Power and Energy Systems 2015, 71, 68-76. doi:10.1016/j.ijepes.2015.02.041.

24. Hurtt, J.; Mili, L. Residential microgrid model for disaster recovery operations. PowerTech (POWERTECH), 2013 IEEE Grenoble. IEEE, 2013, pp. 1-6.

25. Sao, C.; Lehn, P. Autonomous Load Sharing of Voltage Source Converters. IEEE Transactions on Power Delivery 2005, 20, 1009-1016. doi:10.1109/TPWRD.2004.838638.

26. Mohamed, Y.; El-Saadany, E. Adaptive Decentralized Droop Controller to Preserve Power Sharing Stability of Paralleled Inverters in Distributed Generation Microgrids. IEEE Transactions on Power Electronics 2008, 23, 2806-2816. doi:10.1109/TPEL.2008.2005100.

27. Engler, A. Applicability of droops in low voltage grids. International Journal of Distributed Energy Resources 2005, 1, 1-6.

28. Engler, A.; Osika, O.; Barnes, M.; Hatziargyriou, N. DB2 Evaluation of the local controller strategies. European Commission: Brussels, Belgium 2005.

29. Tuladhar, A.; Jin, H.; Unger, T.; Mauch, K. Parallel operation of single phase inverter modules with no control interconnections. Applied Power Electronics Conference and Exposition, 1997. APEC'97 Conference Proceedings 1997., Twelfth Annual. IEEE, 1997, Vol. 1, pp. 94-100. 
30. Guerrero, J.M.; Hang, L.; Uceda, J. Control of distributed uninterruptible power supply systems. IEEE Transactions on Industrial Electronics 2008, 55, 2845-2859.

31. Kim, J.; Guerrero, J.M.; Rodriguez, P.; Teodorescu, R.; Nam, K. Mode adaptive droop control with virtual output impedances for an inverter-based flexible AC microgrid. IEEE Transactions on power electronics 2011, 26, 689-701.

32. Jin, P.; Li, Y.; Li, G.; Chen, Z.; Zhai, X. Optimized hierarchical power oscillations control for distributed generation under unbalanced conditions. Applied Energy 2016. doi:10.1016/j.apenergy.2016.06.075.

33. Shahnia, F.; Majumder, R.; Ghosh, A.; Ledwich, G.; Zare, F. Operation and control of a hybrid microgrid containing unbalanced and nonlinear loads. Electric Power Systems Research 2010, 80, 954-965. doi:10.1016/j.epsr.2010.01.005.

34. Carpinelli, G.; Mottola, F.; Proto, D.; Varilone, P. Minimizing unbalances in low-voltage microgrids: Optimal scheduling of distributed resources. Applied Energy 2017, 191, 170-182. doi:10.1016/j.apenergy.2017.01.057. 35. Salmerón Revuelta, P.; Pérez Litrán, S.; Prieto Thomas, J.; Salmerón Revuelta, P.; Pérez Litrán, S.; Prieto Thomas, J. 4 - Shunt Active Power Filters. In Active Power Line Conditioners; Academic Press, 2016; pp. 107-147. doi:10.1016/B978-0-12-803216-9.00004-3.

36. Jayachandran, J.; Murali Sachithanandam, R. ANN based controller for three phase four leg shunt active filter for power quality improvement. Ain Shams Engineering Journal 2016, 7, $275-292$. doi:10.1016/j.asej.2015.03.007.

37. Golsorkhi, M.S.; Lu, D.D.C. A Decentralized Control Method for Islanded Microgrids under Unbalanced Conditions. IEEE Transactions on Power Delivery 2016, 31, 1112-1121. doi:10.1109/TPWRD.2015.2453251.

38. Blaabjerg, F.; Teodorescu, R.; Liserre, M.; Timbus, A. Overview of Control and Grid Synchronization for Distributed Power Generation Systems. IEEE Transactions on Industrial Electronics 2006, 53, 1398-1409. doi:10.1109/TIE.2006.881997.

39. Guerrero, J.; GarciadeVicuna, L.; Matas, J.; Castilla, M.; Miret, J. Output Impedance Design of Parallel-Connected UPS Inverters With Wireless Load-Sharing Control. IEEE Transactions on Industrial Electronics 2005, 52, 1126-1135. doi:10.1109/TIE.2005.851634.

40. Zhang, Y.; Yu, M.; Liu, F.; Kang, Y. Instantaneous Current Sharing Control Strategy for Parallel Operation of UPS Modules Using Virtual Impedance. IEEE Transactions on Power Electronics 2011, 28, 432-440.

41. Shah, S.; Sensarma, P.S. Three Degree of Freedom Robust Voltage Controller for Instantaneous Current Sharing Among Voltage Source Inverters in Parallel. IEEE Transactions on Power Electronics 2010, 25, 3003-3014. doi:10.1109/TPEL.2010.2050150.

42. Kay-Soon Low.; Runzi Cao. Model Predictive Control of Parallel-Connected Inverters for Uninterruptible Power Supplies. IEEE Transactions on Industrial Electronics 2008, 55, 2884-2893. doi:10.1109/TIE.2008.918474.

43. Harnefors, L.; Bongiorno, M.; Lundberg, S. Input-Admittance Calculation and Shaping for Controlled Voltage-Source Converters. IEEE Transactions on Industrial Electronics 2007, 54, 3323-3334. doi:10.1109/TIE.2007.904022.

44. Yun Wei Li.; Ching-Nan Kao. An Accurate Power Control Strategy for Power-Electronics-Interfaced Distributed Generation Units Operating in a Low-Voltage Multibus Microgrid. IEEE Transactions on Power Electronics 2009, 24, 2977-2988. doi:10.1109/TPEL.2009.2022828.

45. De, D.; Ramanarayanan, V. Decentralized Parallel Operation of Inverters Sharing Unbalanced and Nonlinear Loads. IEEE Transactions on Power Electronics 2010, 25, 3015-3025. doi:10.1109/TPEL.2010.2068313.

46. Xiongfei Wang.; Blaabjerg, F; Zhe Chen. Autonomous Control of Inverter-Interfaced Distributed Generation Units for Harmonic Current Filtering and Resonance Damping in an Islanded Microgrid. IEEE Transactions on Industry Applications 2014, 50, 452-461. doi:10.1109/TIA.2013.2268734.

47. Cheng, P.T.; Chen, C.A.; Lee, T.L.; Kuo, S.Y. A Cooperative Imbalance Compensation Method for Distributed-Generation Interface Converters. IEEE Transactions on Industry Applications 2009, 45, 805-815. doi:10.1109/TIA.2009.2013601.

48. Guerrero, J.; Matas, J.; Garcia De Vicunagarcia De Vicuna, L.; Castilla, M.; Miret, J. Wireless-Control Strategy for Parallel Operation of Distributed-Generation Inverters. IEEE Transactions on Industrial Electronics 2006, 53, 1461-1470. doi:10.1109/TIE.2006.882015. 
49. Kim, J.; Guerrero, J.M.; Rodriguez, P.; Teodorescu, R.; Nam, K. Mode Adaptive Droop Control With Virtual Output Impedances for an Inverter-Based Flexible AC Microgrid. IEEE Transactions on Power Electronics 2011, 26, 689-701. doi:10.1109/TPEL.2010.2091685.

50. Lee, T.L.; Cheng, P.T. Design of a New Cooperative Harmonic Filtering Strategy for Distributed Generation Interface Converters in an Islanding Network. IEEE Transactions on Power Electronics 2007, 22, 1919-1927. doi:10.1109/TPEL.2007.904200.

51. Hamzeh, M.; Karimi, H.; Mokhtari, H. Harmonic and Negative-Sequence Current Control in an Islanded Multi-Bus MV Microgrid. Smart Grid, IEEE Transactions on 2013, PP, 1.

52. Rowe, C.N.; Summers, T.J.; Betz, R.E.; Cornforth, D.J.; Moore, T.G. Arctan Power-Frequency Droop for Improved Microgrid Stability. IEEE Transactions on Power Electronics 2013, 28, 3747-3759. doi:10.1109/TPEL.2012.2230190.

53. Hamzeh, M.; Karimi, H.; Mokhtari, H. A New Control Strategy for a Multi-Bus MV Microgrid Under Unbalanced Conditions. IEEE Transactions on Power Systems 2012, 27, 2225-2232. doi:10.1109/TPWRS.2012.2193906.

54. Guerrero, J.; GarciadeVicuna, L.; Matas, J.; Castilla, M.; Miret, J. Output Impedance Design of Parallel-Connected UPS Inverters With Wireless Load-Sharing Control. IEEE Transactions on Industrial Electronics 2005, 52, 1126-1135. doi:10.1109/TIE.2005.851634.

55. Hamzeh, M.; Karimi, H.; Mokhtari, H. Harmonic and Negative-Sequence Current Control in an Islanded Multi-Bus MV Microgrid. IEEE Transactions on Smart Grid 2014, 5, 167-176. doi:10.1109/TSG.2013.2263842.

56. Ghazanfari, A.; Hamzeh, M.; Mokhtari, H.; Karimi, H. Active power management of multi-hybrid fuel cell/supercapacitor power conversion system in a medium voltage microgrid. IEEE Trans. On Smart Grids 2012, 3, 1903-1910.

57. Akagi, H.; Watanabe, E.H.; Aredes, M. Instantaneous Power Theory and Applications to Power Conditioning; Wiley, 2007.

58. Hamzeh, M.; Karimi, H.; Mokhtari, H.; Mahseredjian, J. Control of a microgrid with unbalanced loads using virtual negative-sequence impedance loop. The 5th Annual International Power Electronics, Drive Systems and Technologies Conference (PEDSTC 2014). IEEE, 2014, pp. 78-83. doi:10.1109/PEDSTC.2014.6799348. 59. Chandorkar, M.; Divan, D.; Adapa, R. Control of parallel connected inverters in standalone AC supply systems. IEEE Transactions on Industry Applications 1993, 29, 136-143. doi:10.1109/28.195899.

60. Karimi, H.; Yazdani, A.; Iravani, R. Negative-Sequence current injection for fast islanding detection of a distributed resource unit. IEEE Transactions On Power Electronics 2008, 23, 298-307.

61. Cooper, C. IEEE recommended practice for electric power distribution for industrial plants. Electronics and Power 1987, 33, 658. 